Document downloaded from:

http://hdl.handle.net/10251/154112

This paper must be cited as:

Fonseca, L.; Novella Rosa, R.; Olmeda, P.; Valle, RM. (2019). Internal Combustion Engine Heat Transfer and Wall Temperature Modeling: An Overview. Archives of Computational Methods in Engineering. 27(5):1661-1679. https://doi.org/10.1007/s11831-019-09361-9

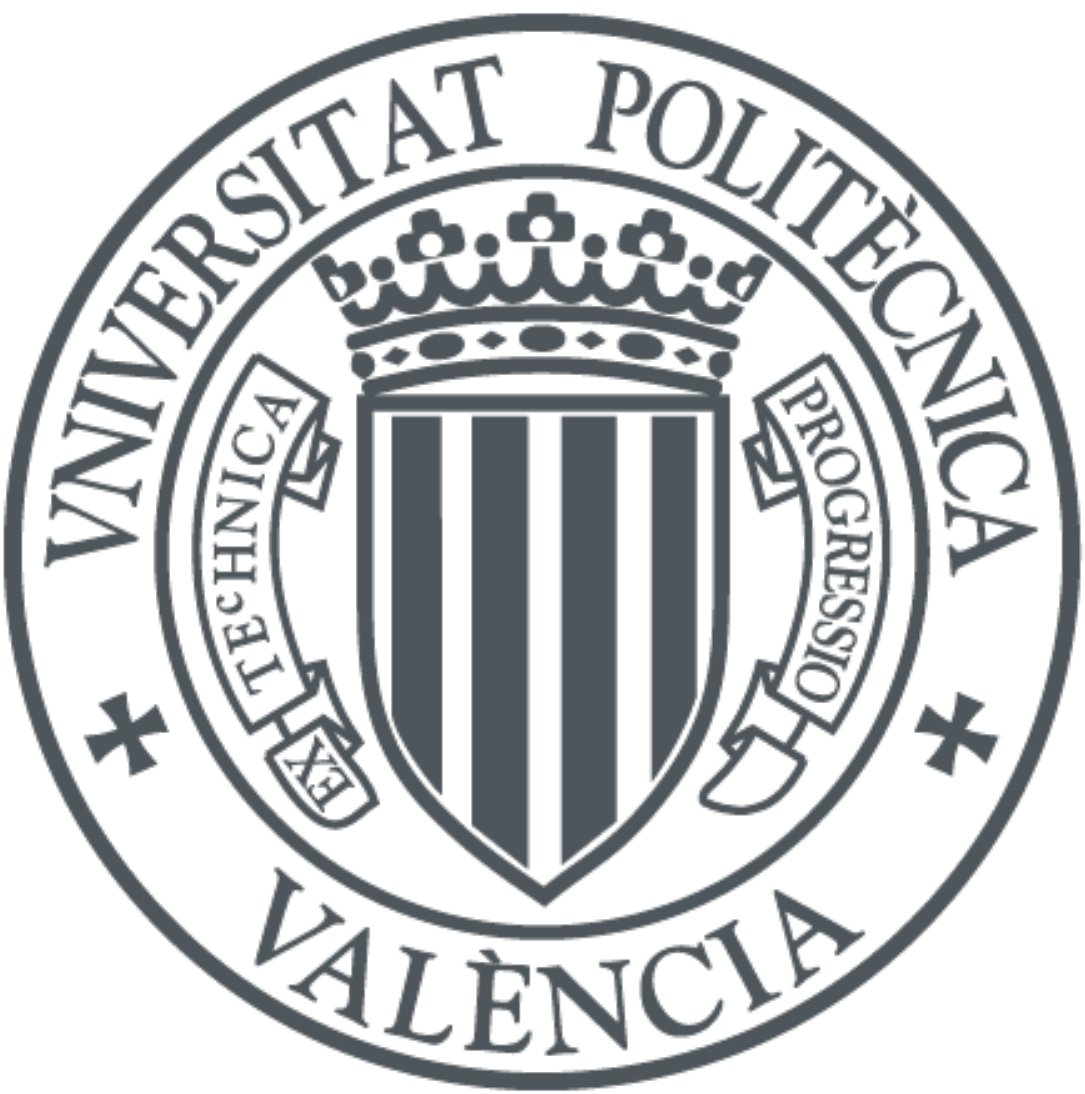

The final publication is available at

https://doi.org/10.1007/s11831-019-09361-9

Copyright Springer-Verlag

Additional Information 


\title{
Internal Combustion Engine Heat Transfer and Wall Temperature Modeling: An Overview
}

\author{
Leonardo Fonseca $^{1,3} \quad \cdot$ Pablo Olmeda $^{2} \quad \cdot$ Ricardo Novella $^{2} \quad \cdot$ Ramon Molina Valle $^{1}$
}

\begin{abstract}
Internal combustion engines are now extremely optimized, in such ways improving their performance is a costly task. Traditional engine improvement by experimental means is aided by engine thermodynamic models, reducing experimental and total project costs. For those models, accuracy is mandatory in order to offer good prediction of engine performance. Modelling of the heat transfer and wall temperature is an important task concerning the accuracy and the predictions of any engine thermodynamic model, although it is many times an overcome task. In order to perform good prediction of engine heat transfer and wall temperature, models are required for accomplish heat transfer from hot gases to engine parts, heat transfer inside each engine part, and also heat transfer to coolant and lubricating oil. This paper presents an overview about engine heat transfer and wall temperature modelling, with main purpose to aid engine thermodynamic modelling and offer more accurate predictions of engine performance, consumption and emission parameters. The most important correlation are reviewed for three engine heat transfer approaches: gas to wall, wall to wall and wall to liquid heat transfer models. In order to obtain good prediction of wall temperature, those three approaches must be coupled, which may imply convection-conduction-convection problems, although for some applications in diesel engines, radiation problems must be considered.
\end{abstract}

Keywords Internal combustion engine $\cdot$ Engine wall temperature modeling $\cdot$ Engine heat transfer modelling $\cdot$ Engine thermodynamic modelling

\section{Introduction}

The global awareness towards the greenhouse gases emissions has led to a more stringent Internal Combustion Engine (ICE) emissions legislation, thus focusing the automotive researchers and manufacturers attention on the development

The author Leonardo Fonseca acknowledges CAPES

(Coordination for the Improvement of Higher Education

Personnel) for the scholarship from the program "CAPES -

DEMANDA SOCIAL”, Ph.D. level.

Leonardo Fonseca

leofonseca@ufmg.br

1 PPGMEC/UFMG - Mechanical Engineering Post Graduation Program - Federal University of Minas Gerais, 6627 Antonio Carlos Av., Belo Horizonte 31270-901, Brazil

2 CMT Motores Termicos, Universitat Politècnica de València, Camino de Vera s/n, 46022 Valencia, Spain

3 DETEM/UFSJ - Telecommunications and Mechatronic Engineering Department - Federal University of São João del-Rei, MG 443, km 7, Ouro Branco 36420-000, Brazil of cleaner and more efficient powertrains [1]. After decades of optimization research and design, Internal Combustion Engine (ICE) are now extremely optimized, in such a manner that improving their performance is really difficult.

Experimental research has always been the main option in engine development, although it is very expensive. Simulation tools that predict the engine cycle are frequently used in the development of new engines. The accuracy of the simulation results depends on the accuracy of the underlying models $[2,3]$.

In the past few decades, engine CFD 3D simulation has become an attractive option, specially for aiding experimental methods and reducing its cost. In order to aid experimental methods, accuracy is required from engine CFD 3D modelling. The implementation of different engine thermodynamic models depends on the wall temperature used, in order to offer more accurate results. This way, both researchers and engineers need to model or measure properly wall temperatures if they want accuracy.

Research on in-cylinder heat transfer of internal combustion engines has been conducted since 1923 [4], in order to 
optimize engine design, due to the significant impact of heat transfer on engine's efficiency, power and emissions [2, 5, 6]. Prediction of heat transfer plays an important role in engine development as heat losses influence overall engine efficiency, exhaust emissions and component thermal stresses [7]. By modeling engine heat transfer, design changes can be readily assessed with minimal prototype construction and testing. This enables new engines to be designed more rapidly, cost effectively, and with improved thermal signatures [8].

In the past few decades, several research efforts has shown that engine wall temperatures change considerably for different operating conditions, specially on what concerns wall heat transfer. The wall heat transfer can contribute to a significant heat loss in the overall fuel conversion process, and the in cylinder combustion processes and engine operation can also be affected. In addition, the wall heat flux determines the distribution of thermal stress in the mechanical components of the engine.

The measurement of wall temperatures is an expensive alternative, once the most used techniques nowadays involves drilling operations that usually modify the measured engine, or makes it unable to operate. Other measurement techniques involves state of the art equipment or newly developed optical techniques [9], which are expensive. Both estimation and calculation of engine heat transfer depends on proper wall temperature modelling. There are many different models for heat transfer calculation on internal combustion engines, although most of those models do not calculate wall temperature.

There are lots of different ways to measure or model internal combustion engine heat transfer and wall temperatures. It is the purpose of this paper to review internal combustion engine heat transfer and wall temperature modelling. The state of the art concerning those subjects is described, and a link between engine heat transfer modelling and thermodynamic modelling is highlighted. This way, the engineer or researcher involved in engine design and optimization which needs proper estimation/calculation of engine wall temperature values, should take note at this review and chose the option that best fits its goals and resources.

This paper is organized as follows. In Sect. 2, ICE thermodynamic modelling is briefly described as the main tool for aiding engine development, and the importance of heat transfer models and wall temperature values as boundary conditions for the first law of thermodynamics is described. In Sect. 3, ICE Heat transfer and wall temperature modelling are reviewed and classified in three main heat transfer phenomena: gas to wall(convection and radiation problems), wall to wall(conduction and contact resistance problems) and wall to liquid(convection problems) values. The gas to wall classification contains the heat transfer phenomena most widely studied and published concerning internal combustion engine application, in such a manner that some regions of the engine are described separately. The wall to wall classification contains specifically heat transfer phenomena through solid media inside the engine, and the methods to solve this heat transfer problem. Finally, the wall to liquid classification contains heat transfer phenomena associated with coolant liquid and lubricating oil. In Sect. 4, the main topics of this review are summarized.

\section{ICE Thermodynamic Modelling}

Engine thermodynamic models are valuable tools for engineers either working in the automotive industry or belonging to the research community, with the aim to design engines that comply with the strict emissions legislation while keeping high performance [10-12]. High cost experimental tests are increasingly replaced by cheap system simulations of the engine. With current trends like alternative fuels, downsizing, EGR, multiple spark plugs per cylinder, etc. it is indeed no longer possible for an $R \& D$ engineer to intuitively grasp how these factors will affect the engine operation. The employed engine models are obviously required to reproduce any fuel specific effects on the combustion process [13].

Thermodynamic models are the subject of earlier overview paper [14]. From the thermodynamic point of view, several model frameworks are used for the simulation of the closed part of spark-ignition and compression ignition engine cycle, these can be classified as [14]:

- zero-dimensional

- multi-zone

- multi-dimensional

Those three categories of engine thermodynamic modelling are the subject of comparison for some authors. Pariotis et al. [10] compared the results obtained using a zerodimensional, a multi-zone and a multi-dimensional model, all of them applied to the simulation of a high speed single cylinder diesel engine. The engine operates in motoring conditions, from 1200 until $3000 \mathrm{rpm}$. The zero-dimensional model calculates with reasonable accuracy the in-cylinder pressure, while it rather underestimates the mean gas temperature near the top dead center (TDC) compared to the other two models, meanwhile it has the minor computational time. The multi-zone model provides information for the local in-cylinder temperature distribution and describes qualitatively correctly the effect of the cylinder on the flow field.

The first two types are classified as phenomenological models, where the equations constituting the basic structure of the model are based on conservation of mass and energy and are only dependent on time (resulting in ordinary 
differential equations) [14]. Multidimensional models are also termed fluid mechanic or fluid dynamic models, where the governing equations are the Navier-Stokes equations in addition to conservation of mass and energy (the equations are also dependent on the spatial coordinates, and so take the form of partial differential equations) [14].

Independently from its type, the accuracy of thermodynamic models is affected by both heat transfer models and wall temperature values, once heat transfer models are part of the solution of the first law of thermodynamics, and wall temperatures are boundary conditions for the heat transfer models. The wall heat transfer can contribute to a significant heat loss in the overall fuel conversion process, and the in cylinder combustion processes and engine operation can also be affected. In addition, the wall heat flux determines the distribution of thermal stress in the mechanical components of the engine. Consequently, an accurate calculation of the chamber wall heat transfer is essential to improve the performance of engine simulation, which thereby can be more helpful in the design of more fuel efficient engines [15].

Several models have been developed to estimate/calculate the heat fluxes from engine gas flows at intake, exhaust and inside the cylinder to the respective walls. These models are focused on the detailed modeling of thermal boundary layer in the fluid phase near the wall and are mostly based on the assumption of constant wall temperature. Recent measurement of engine wall temperatures shows differences from the cylinder head hot regions to cylinder head and cylinder liner cold regions as high as $50 \mathrm{~K}$ for a single engine operating condition [16]. This way, constant wall temperature is not realistic assumption and can introduce significant errors in estimating the heat flux on cylinder wall [15] . To achieve more accurate calculation of heat fluxes involving different heat transfer phenomena inside the engine, different models and approaches have been developed and are the main subject of Sect. 3 .

\subsection{Zero-Dimensional Models}

Zero-dimensional models (also termed single-zone models) are based on mass and energy balance, applied to the combustion chamber of a given engine. Those models use a predefined mass burning rate, of which the Wiebe law is the best known example. This mass burning rate has to be empirically defined for every engine operating point, on the basis of prior engine experiments or experience and is not expressed in terms of physical quantities (e.g. fuel properties, engine geometry, etc.) rendering extrapolation to other problematic operating conditions [14].

Pariotis et al. [10] used a single zone model, based on the first law of thermodynamics to resolve the closed cycle of single cylinder diesel engine. This model is coupled to a turbulence $\mathrm{k}-\epsilon$ simplified model using the heat transfer model. This model was able to predict well the in-cylinder temperature trace, but could only estimate in-cylinder temperature, meanwhile it was able to resolve the closed cycle in only $1 \mathrm{~s}$ using a personal computer.

Rashedul et al. [17] used a single zone model to study convective heat transfer inside a spark ignition engine fueled with bioethanol. The thermodynamic model is a single zone one, based on the first law of thermodynamics.

Benajes et al. [18] used two different 0D models to perform global energy balance concerning a 4 cylinder high speed direct injection turbocharged diesel engine, and evaluate the effect of swirl on the global energy balance of the evaluated engine.

\subsection{Multi-zone Models}

Multi-zone models are distinguished from zero-dimensional models by the inclusion of certain geometrical parameters in the basic thermodynamic approach. This usually involves the radius of a thin interface (the flame) separating burned from unburned gases, resulting in a 'two-zone' formulation [14].

Pariotis et al. [10] used a quasi-dimensional model as a hybrid one, meaning that it used phenomenological submodels to describe the various processes taking place inside combustion chamber. Phenomenological sub-models are used to describe: heat transfer through the cylinder walls, fuel injection rate, fuel spray penetration, evaporation, combustion and pollutant formation. The computational domain covers the whole cylinder volume and is divided into computational cells, in order that a series of characteristic properties $\phi$ of the flow field is calculated at each cell, by solving conservation equation of each property at each cell. The results for multi-zone model show good agreement with CFD 3D results for in-cylinder pressure trace, mean gas temperature and heat transfer, along with a good estimation of flow field velocities.

Vancoillie et al. [13] published the development and validation of a quasi dimensional model for methanol and ethanol fueled SI engines. The authors presented the evaluation and comparison of the developed model for different correlations of turbulent burning velocity, laminar burning velocity and knock prediction sub-model, as those correlations are implemented in the quasi dimensional power cycle model.

\subsection{Multi-dimensional Modelling}

Multidimensional engine combustion simulation has been an active area of research, where advanced physical and chemical models continue to be developed [15]. Since early 90's, several papers have been published concerning application of engine CFD 3D modelling to better understand in cylinder phenomena, and propose engine optimization [19-21]. Nowadays, different approaches involving engine CFD 3D 
are used for academic or industry purposes, in order to perform engine optimization. [3, 22-24]

di Mare et al. [24] presented the application of LES quality criteria to internal combustion engine CFD 3D simulations, using a commercial CFD 3D code.

Zhang [15] implemented into a KIVA-4V code a solid domain heat transfer solver, in order to perform simultaneously in cylinder thermal fluid dynamic calculation and wall heat transfer. The author proposed a vertical partition scheme for mesh sector, in order to reduce computational timing. Other strategy used to reduce computational cost is to use cylinder symmetry and simulate only in cylinder phenomena, this way only the closed cycle is calculated for several cycles, until wall temperature reaches a steady state condition. The equations for thermal fluid dynamics processes (mass, momentum and energy conservation, coupled to several sub-models) are adapted to solve solid phase heat flux at cylinder head, liner and piston.

\subsection{Summary of ICE Thermodynamic Modelling}

There are different approaches for engine thermodynamic modeling, being those different models represented in three different groups in this paper. The different engine thermodynamic models have in common need for proper heat transfer and wall temperature modelling, as boundary conditions for the first law of thermodynamics, in order to offer accurate results for in cylinder phenomena.

\section{ICE Heat Transfer and Wall Temperature Modeling}

The importance of heat transfer for engine design and optimization has been highlighted by several authors in literature. The reasons are the accurate calculation of performance parameters, fuel consumption and emissions. Still nowadays heat transfer and wall temperature measurements are not always an option for internal combustion engine design and optimization, this way the models for this kind of application are the only alternative in many situations for estimation/ calculation of heat transfer and wall temperature. Historically, the first model for engine heat transfer was presented by Nusselt (1923), based on experiments in a spherical bomb [4].

In this section, the models presented in literature for estimation/calculation of engine heat transfer and wall temperature are reviewed. These models are organized in three heat transfer modelling approaches as follows:

1. Gas to wall heat transfer;

2. Wall to wall heat transfer;

3. Wall to liquid heat transfer.
Gas to wall heat transfer is the modelling approach for the heat exchange between gases and walls in cylinder, intake and exhaust engine regions. Most of the papers in literature addressing heat transfer inside internal combustion engines refers exclusively to this heat transfer approach. Wall to wall heat transfer approaches are those used to calculate heat fluxes inside engine parts (head, piston, valves, block, etc.). The third modelling approach is dedicated to calculate heat flux to coolant and lubricating oil.

The combination of gas to wall, wall to wall and wall to liquid approaches is required to estimate/calculate engine internal wall surface temperature, inside the cylinder, ports and ducts, and specially for valves and piston. For any kind of engine, using those approaches means working with convection-conduction problems, although in diesel engines, it can involve radiation in some cases (very sooting flames).

Internal combustion engine heat transfer modeling has been the subject of earlier review papers $[4,25]$ and were deeply discussed in PhD thesis [26].

Borman and Nishiwaki [4] published a review about internal combustion engine heat transfer. They described the state of the art about engine heat transfer modeling at that time. The authors reviewed the most important correlation for heat exchange between gases and walls inside the air ducts of an internal combustion engine, on what concerns in cylinder heat transfer, prechamber, gas exchange process and intake and exhaust system. Most of the models presented involves empirical and semi empirical correlations for heat transfer between gases and walls, although there are some radiant heat transfer models. There are also some one dimensional and multidimensional models described. It was an important review at the time, and still nowadays it is used in the literature [15, 27-31].

Although it is used until nowadays, Borman and Nishiwaki review addresses specifically gas to wall heat transfer modelling. Several models for this engine heat transfer approach have been proposed since, but there was also models proposed for other engine heat transfer approaches. It is the purpose of this section to update the state of the art on the subject of models for heat exchange between gases and wall inside internal combustion engines, and also review models for heat transfer between engine parts and from engine parts to lubricating oil and coolant.

Most of the correlations that have been developed over the past eighty years provide spatially averaged heat-transfer coefficients [32].

The use of the three heat transfer approaches coupled can be found in some applications, for example in order to perform CHT (conjugate heat transfer) analysis where those heat transfer approaches are coupled to any engine thermodynamic model like the ones described in Sect. 2. Figure 1 illustrates the use of three heat transfer approaches coupled in order to obtain heat transfer and temperature calculations. 


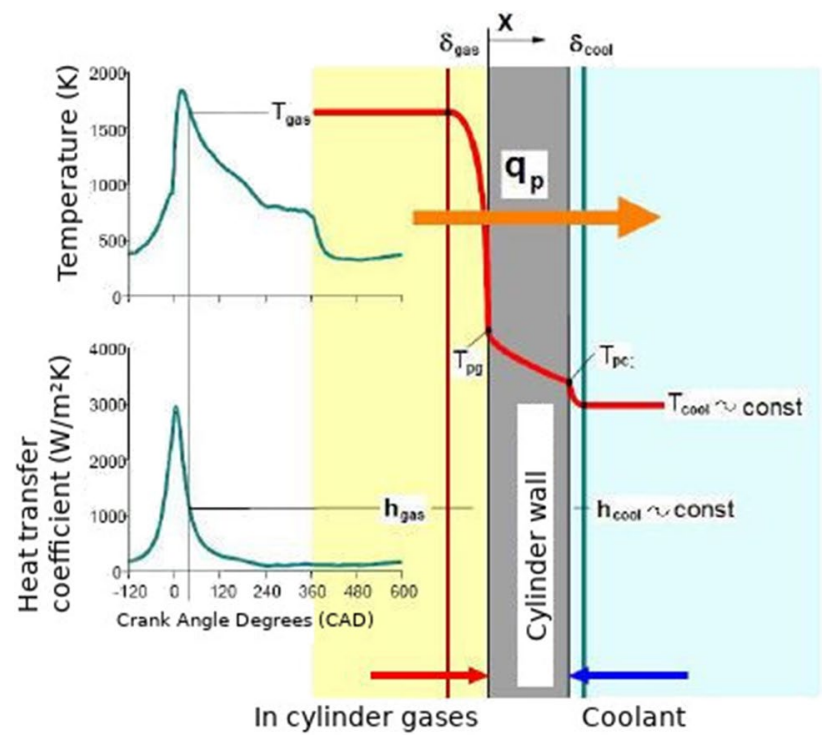

Fig. 1 Combination of different heat transfer approaches for wall heat transfer and temperature estimation/calculation. [26]

Benajes at al. [18] used a lumped conductance model to calculate wall temperatures in the chamber and ports along with the heat rejection repartition to coolant and oil, coupled to a OD thermodynamic model, in order to perform global energy balance in an 4 cylinder diesel engine. It is also possible to use the three heat transfer approaches coupled to a thermodynamic model in order to provide boundary conditions for engine thermodynamic modelling, specially CFD 3D models.

\subsection{Gas to Wall Heat Transfer}

The engine heat transfer modeling approach most widely studied and used is in cylinder gas to wall heat transfer. Nevertheless, there are studies for this heat transfer approach concerning heat transfer between gas fluxes and valves [33], and also concerning heat transfer between gas fluxes and intake and exhaust ports $[34,35]$. Once most of the studies involves exclusively in cylinder heat transfer, the heat transfer from the other regions is frequently neglected or even forgotten. Although, once the calculation of the ducts surfaces temperatures is a target for modelling accuracy, those regions heat transfer approaches can't be neglected.

The heat transfer between gas fluxes and walls for each surface in contact with in cylinder gases is modeled by the correlations proposed for in cylinder gas to wall heat transfer. For other surfaces, like valve stem and seat, correlations for gas flow through different ducts are used. Correlations for heat transfer similar to those for mass flux through valve curtain flow area are used for valve seat, meanwhile heat transfer for flow over a flat plate and cross flow over a cylinder are coupled to describe heat transfer at valve stem. For gas to wall heat transfer at the ports, correlations for turbulent flow over curved ducts are used.

\subsubsection{In Cylinder Heat Transfer Modelling}

The engine heat transfer phenomena most widely reported occurs from hot gases inside combustion chamber towards engine internal surfaces at cylinder head, cylinder liner, piston and valve faces. Several authors refers to this heat transfer mode as engine heat transfer only, although in this review other internal combustion engine heat transfer phenomena are under discussion. In cylinder heat transfer is among the most complicated of engineering heat transfer problems, involving rapid changes in gas temperature, pressure and velocity, together with local complexities of velocity and temperature distribution [4]. Most of the common gas to wall heat transfer models rely on the definition of the wall heat flux $q^{\prime \prime}$ using Newton's cooling law [36]:

$q^{\prime \prime}=h\left(T-T_{w}\right)$

with the heat transfer coefficient $h$, and the difference between gas temperature $T$ and wall temperature $T_{w}$ [36]. The early models of Nusselt, Eichelberg and Pflaum contain dependencies of $h$ on engine specific parameters like cylinder pressure $p$, cylinder temperature $T$, and mean piston speed $v_{p} m[36,37]$. To overcome this weakness, later model concepts are based on similarities using non dimensional properties. The wide spread models of Annand [38] and Woschni [39] are based on the convective part of the heat transfer adopted from the boundary layer theory:

$N u=C \operatorname{Re}^{a} \operatorname{Pr}^{b}$

The Nusselt number $\mathrm{Nu}$ characterizes the non dimensional heat transfer depending on the Reynolds number Re, which covers the flow characteristics, and the physical fluid properties described by the Prandtl number, $\operatorname{Pr}$ [36].

Since Borman and Nishiwaki review, great quantity of new papers have been published on this subject.

Some authors evaluate the most used correlations, and test their accuracy against experimental data on engine heat transfer.

Han et al. [40] compared the predictions for instantaneous heat transfer coefficient and time averaged heat transfer coefficient calculated using 4 different empirical formulations: Woschni, Hohemberg, Eichelberg and Yoshida. The authors concluded that the time averaged values match the experimental ones, but the instantaneous values does not present good agreement with the experimental ones.

De Cuyper et al. [41] used a 4 cylinder 1.81 engine, equipped with TFG (thin film gauge) sensors to evaluate empirical heat transfer correlations suggested by Annand and Woschni. They used only those correlations because 
those are the most commonly used in commercial software for apparent heat release calculation. The results for instantaneous heat flux show considerable difference between the values calculated by heat transfer correlations and the values calculated based on the data measured by thin film gauges. On the other hand, the values for total heat transfer predicted by the models are similar to the measured ones.

Other authors propose new correlations, with or without comparison to the traditional ones.

Irimescu et al. [42] developed a correlation for gas to wall heat transfer inside a single cylinder optical engine, based on thermodynamic and optical measurements. The correlation is developed considering the effect of the combustion process into the flow field after top dead center until half expansion stroke, using the cascade model of kinetic energy transfer. Each eddy is considered half of a jet, emerging from a tube with diameter $\mathrm{L}$, impinging over a flat plate at a distance of $\mathrm{L} / 2$ from the tube's edge, where $\mathrm{L}$ is the characteristic length taken as the clearance height $h_{c}$ until half of the expansion stroke. The developed correlation for the Nusselt number is:

$N u=0.037 \operatorname{Re}^{0.8} \operatorname{Pr}^{0.33}{\frac{T}{T_{w}}}^{0.11}$

The last term on the right side of the equation is a correction accounting for the temperature difference of the fluid within the boundary layer. Along with this expression, an additional term is added to the characteristic velocity, taking the combustion process as an addition to the kinetic energy of the fluid. The developed model is compared to traditional models of Woschni [39] and Annand [38], and all of the models are compared to experimental measurements. The authors found that the developed model has similar results to the traditional correlations.

Olmeda et al. [1] developed a correlation for estimation of in cylinder heat transfer coefficient $h$ between gases and walls, considering the influence of intake air tumble motion on this coefficient. The authors proposed the modification based on a theoretical review about heat transfer coefficient, performed the modification based on CFD 3D simulations, and calibrated the new model based on experimental results obtained in a single cylinder 2 stroke diesel engine operating under skip firing condition. The equation proposed by the authors for the heat transfer coefficient $h$ is:

$h=C D^{-0.2} p^{0.8} T_{g}^{-0.55} v_{t}^{0.8}$

here $C$ is a constant, $D$ is cylinder bore, $p$ and $T_{g}$ are, respectively, in cylinder gas pressure and temperature, and $v_{t}$ is a tumble generated gas velocity, defined as:

$v_{t}=C_{t 1} c_{m}+C_{t 2} \bar{v}_{m} f_{w}+C_{2} \frac{V_{d} T_{I V C}}{V_{I V C} P_{I V C}}\left(p-p_{0}\right)$
The gas velocity is proportional to a tumble gas velocity dissipation function, $f_{w}(\alpha)$, which depends on the crank angle, and a characteristic mean gas velocity $\bar{v}_{m}$, respectively defined as:

$f_{w}(\alpha)=\exp ^{a\left(\frac{\alpha-\alpha_{0}}{\alpha_{f}-\alpha_{0}}\right)^{m}}$

$\bar{v}_{m}=\frac{360 \eta_{t r} \dot{m}_{a}}{A_{\text {eff }} \bar{\rho}_{a} \Delta \alpha_{I V O-I V C}}$

The characteristic mean gas velocity is calculated based on the mean air density during intake process, calculated using a mean gas in cylinder temperature $\bar{T}_{c y l, i n t}$ :

$\bar{T}_{c y l, i n t}=\bar{T}_{i n t}\left(\frac{\bar{p}_{c y l, i n t}}{\bar{p}_{\text {int }}}\right)^{\frac{\gamma-1}{\gamma}}$

The model proposed obtained a $70 \%$ reduction on the root mean square error, compared to the reference Woschni based model.

Michl et al. [36] derived and validated a heat transfer correlation for hydrogen engines. The authors have based their model in the Nusselt Reynolds relation for turbulent pipe flow to calculate the heat transfer coeffient $h$, and calculated the fluid properties using multizone approach based on a CHEMKIN based stirred reactor analysis of hydrogen combustion reaction.

$h=C \cdot L_{c} \cdot \Omega \cdot v_{c} \cdot \Xi$

where $C$ is a constant and $\Xi$ is an explicit term for the augmentation of heat transfer during combustion. In (9) $L_{c}$ is the characteristic length, $\Omega$ is a term to account for property characteristics of hydrogen burning mixture, $v_{c}$ is a characteristic speed using a series of correlations proposed by [36], respectively calculated by:

$L_{c}=D^{-0,23}$

$\Omega=k\left(\frac{\rho}{\nu}\right)^{0,77}$

here $k$ is thermal conductivity and $\eta$ is kinematic viscosity, calculated for hydrogen burning mixture using:

$k=y_{\text {air }} k_{\text {air }}+y_{H 2} k_{H 2}+y_{b} k_{b}$

$k_{\text {air }}=2,8610^{-4} T^{0.785}$

$k_{H 2}=2,3210^{-3} T^{0.760}$

$k_{b}=7,3610^{-5} T^{1.031}$

$\eta=y_{\text {air }} \eta_{\text {air }}+y_{H 2} \eta_{H 2}+y_{b} \eta_{b}$

$\eta_{\text {air }}=4,3910^{-7} T^{0.662}$ 
$\eta_{H 2}=2,2710^{-7} T^{0.646}$

$\eta_{b}=1,8010^{-7} T^{0.779}$

The validation was performed based on experiments on a single cylinder, 4 valve, direct injection spark ignition engine. The authors installed 14 thermocouples in the engine head surface, and 15 thermocouples in the piston surface, being every thermocouple $2 \mu \mathrm{m}$ thickness.

It has been highlighted in this subsection that the cumulative heat flux predicted by Woschni model, and also other traditional models, shows good agreement to experimental values, in most cases. On the other hand, it has been published by several authors that instantaneous heat flux values calculated by Woschni model, and also other traditional models, do not fit experimental data. It has also been highlighted that some authors propose specific correlations, intending to improve accuracy of traditional model predictions for specific cases, like hydrogen engines [36] and high tumble engines [1].

\subsubsection{Valves Heat Transfer Modelling}

Heat transfer from gas fluxes to valve surfaces is also a complex phenomena, once different valve surface regions are submited to different heat transfer phenomena.

Cerdoun et al. [33] performed a heat transfer analysis for intake and exhaust valves inside internal combustion engines, considering the heat flow through the valve and the different boundary conditions involved in valves operations. The authors used the Woschni correlation to estimate the heat transfer coefficient, and calculate the heat flux from the gases inside the combustion chamber to the valve surface in contact with the gases inside the cylinder.

For the valve seat heat transfer modelling, the authors have considered two main situations: closed valve, which is modeled using a thermal resistance model (Sect. 3.2); open valve, which is modeled similar to the flow modelling through a restriction. The mass flow rate through engine valves is modelled as a compressible flow through a restriction, with three different approaches based on the minimum flow area depending on the valve lift. The Reynolds number for compressible flow through a restriction is calculated using:

$R e=\frac{C_{d} D_{h} P_{0}}{\mu\left(R T_{0}\right)^{\frac{1}{2}}}\left(\frac{P_{t}}{p_{0}}\right)^{\frac{1}{\gamma}}\left[\frac{2 \gamma}{\gamma-1}\left[1-\left(\frac{P_{t}}{p_{0}}\right)^{\frac{\gamma-1}{\gamma}}\right]\right]^{\frac{1}{2}}$

If the mass flow rate is modelled this way, the energy flow rate is modeled similarly, in such a way the authors used different correlations for Nusselt number depending on the valve lift, and consequently on the minimum flow area. At low and medium valve lift, hydraulic diameter $D_{h}=\frac{4 A_{\min }}{P_{e r}}$ is used, and Nusselt numbers is calculated using Dittus-Boelter correlation:
$N u=0.023 \operatorname{Re}^{0.8} \operatorname{Pr}^{0.4}$

On the other hand, for high lift, Nusselt number is calculated using Churchill and Bernstein correlation:

$$
N u=0.3+\frac{0.62 \operatorname{Re}^{\frac{1}{2}} \operatorname{Pr}^{\frac{1}{3}}}{\left[1+\left(\frac{0.4}{P r}\right)^{\frac{2}{3}}\right]^{\frac{1}{4}}}\left[1+\left(\frac{R e}{282,000}\right)^{\frac{5}{8}}\right]^{\frac{-4}{5}}
$$

The last region of the valve modeled for gas to wall heat transfer is named by the authors stem port region.

This region is modeled by the authors only for the open valve case, once the heat transfer correlation presented takes into account gas flow condition only.

For this condition, the authors model the valve stem heat transfer coefficient $h$ as the sum of that for a flat plate and for a cylinder, once the flow through the valve stem usually is not either normal or parallel to the valve axis, being generally a composition of those two extreme conditions:

$h_{\text {stem-port }}=\epsilon_{\text {stem-port }} h_{\text {cylinder }}+\left(1-\epsilon_{\text {stem-port }}\right) h_{\text {flatplate }}$

For $h_{\text {flatplate }}$ :

$N u=0.3+\frac{0.62 \operatorname{Re}^{\frac{1}{2}} \operatorname{Pr}^{\frac{1}{3}}}{\left[1+\left(\frac{0.4}{P r}\right)^{\frac{2}{3}}\right]^{\frac{1}{4}}}\left[1+\left(\frac{R e}{282,000}\right)^{\frac{5}{8}}\right]^{\frac{-4}{5}}$

For $h_{\text {cylinder }}$ :

$N u=0.037 \operatorname{Re}^{0.8} \operatorname{Pr}^{0.33}$

Heat transfer for valves and from valves must be modeled carefully, once exhaust valve has the most severe thermal load and is cooled only by the valve seat. On the other hand, intake valve can influence intake charge specific mass.

\subsubsection{Ports Heat Transfer Modelling}

Shayler et al. [34] have performed heat transfer and temperature measurements in the intake port of an internal combustion engine, than used the measured values to adjust a heat transfer correlation. They compared their adjusted correlation, and verified that it indicates that heat transfer arising from gas flow on a firing engine is approximately double that predicted for steady flow results by Martins and Finlay [43].

$N u=0.135 R e^{0.713}$

\subsubsection{Wall Functions}

Multidimensional thermodynamic models need an approach to model heat transfer from cells close to wall regions and the walls. This is used where only one cell 
makes the transition from the main flow to the wall region. The equations that represent the boundary layer for this kind of application are named wall functions.

Fan et al. [27] performed CFD-3D simulations of a spark ignition engine under motoring conditions, using detached eddy simulation for turbulence modelling. The authors used PIV measurements on the center of the combustion chamber of an optical direct injection spark ignition, in order to validate the results of the CFD-3D model. The results are compared in the center of the cylinder, the macro scale flow field region, because the measurement in the region close to the wall is a challenging task due to the curvature of the optical window.

Ma et al. [32] compared traditional wall functions used in CFD 3D commercial codes, based on boundary layer equilibrium conditions, with a wall function developed using micro particle image velocimetry. The results show that the equilibrium wall functions perform well the shear velocity calculation within the viscous sublayer, but show substantial deficiencies if the matching location is outside the viscous sublayer.

Šarić et al. [7] simulated a $90^{\circ}$ edge CFD 3D model of a disk-shaped spark ignition engine, using the turbulence model $k-\zeta-f$ and a hybrid wall heat transfer model implemented in a commercial code. The authors compared the hybrid formulations with standard ones, and used measured data available in literature to validate the comparison.

The heat transfer models used as wall functions are specific for gas to wall heat transfer in multidimensional thermodynamic models.

\subsubsection{Summary of Gas to Wall Heat Transfer Correlations}

Tables 1 and 2 summarize the most recent reviewed correlation related to engine gas to wall heat transfer correlations. Some correlations are proposed based on widely used Woschni [39] and Annand [38] correlations, for specific cases of high tumble and hydrogen engines. The correlations used for valve heat transfer, and also port wall heat transfer are summarized.

Along with Tables 1 and 2, it is important to highlight that the authors in literature who tested traditional gas to wall heat transfer correlations showed that those correlations do not perform well for instantaneous heat flux values, although they perform well for calculation of total heat flux for combustion analysis.

The group of correlations for gas to wall heat transfer provides heat transfer calculation from gas fluxes to ducts surfaces, when evaluating engine behaviour. Only in the case of intake port the heat transfer tends to occur from duct wall to gas.

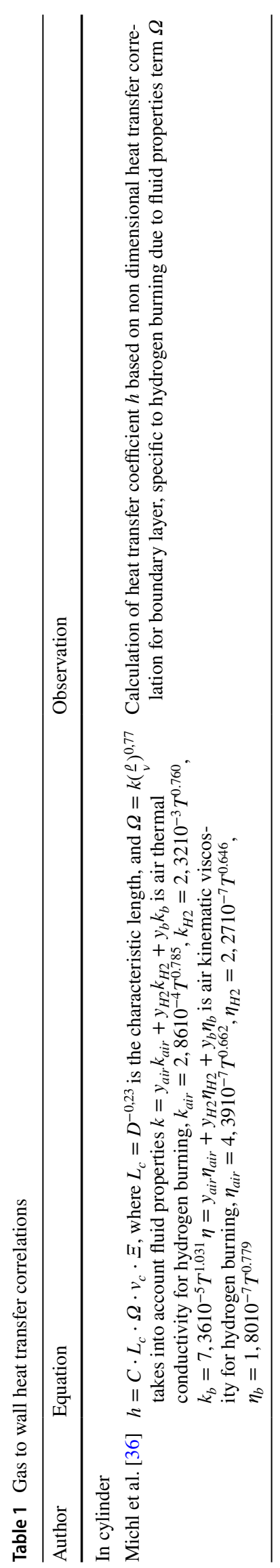


Table 2 Gas to wall heat transfer correlations

\begin{tabular}{|c|c|c|}
\hline Olmeda et al. [1] & $\begin{array}{l}h=C D^{-0.2} p^{0.8} T_{g}^{-0.55} v_{t}^{0.8}, \text { where } v_{t}=C_{t 1} c_{m}+C_{t 2} \bar{v}_{m} f_{w}+C_{2} \frac{V_{d} T_{I V C}}{V_{I V C} P_{I V C}}\left(p-p_{0}\right) \\
\text { is a tumble generated gas velocity, } f_{w}(\alpha)=\exp ^{a\left(\frac{\alpha-\alpha_{0}}{\alpha_{f}-\alpha_{0}}\right)^{m}, \bar{v}_{m}=\frac{360 \eta_{t r} \dot{m}_{a}}{A_{e f f} \bar{\rho}_{a} \Delta \alpha_{I V O-I V C}}} \\
\text { and } \bar{T}_{c y l, \text { int }}=\bar{T}_{\text {int }}\left(\frac{\bar{p}_{c y l, \text { int }}}{\bar{p}_{\text {int }}}\right)^{\frac{\gamma-1}{\gamma}}\end{array}$ & $\begin{array}{l}\text { Expression for calculation of heat transfer } \\
\text { coefficient } h \text {, based on Woschni correla- } \\
\text { tion, specific for engines with increased } \\
\text { tumble motion }\end{array}$ \\
\hline \multicolumn{3}{|c|}{ 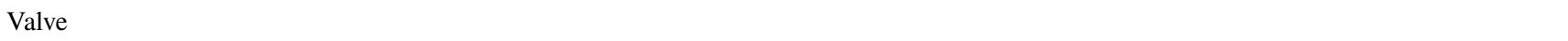 } \\
\hline \multirow[t]{6}{*}{ Cerdoun et al. [33] } & $R e=\frac{C_{d} D_{h} P_{0}}{\mu\left(R T_{0}\right)^{\frac{1}{2}}}\left(\frac{P_{t}}{p_{0}}\right)^{\frac{1}{\gamma}}\left[\frac{2 \gamma}{\gamma-1}\left[1-\left(\frac{P_{t}}{p_{0}}\right)^{\frac{\gamma-1}{\gamma}}\right]\right]^{\frac{1}{2}}$ & \\
\hline & $N u=0.023 R e^{0.8} \operatorname{Pr}^{0.4}$ & \\
\hline & $N u=0.3+\frac{0.62 \operatorname{Re} e^{\frac{1}{2}} \operatorname{Pr}^{\frac{1}{3}}}{\left[1+\left(\frac{0.4}{P_{r}}\right)^{\frac{2}{3}}\right]^{\frac{1}{4}}}\left[1+\left(\frac{R e}{282,000}\right)^{\frac{5}{8}}\right]^{\frac{-4}{5}}$ & \\
\hline & $h_{\text {stem-port }}=\epsilon_{\text {stem-port }} h_{\text {cylinder }}+\left(1-\epsilon_{\text {stem-port }}\right) h_{\text {flatplate }}$ & \\
\hline & $N u=0.3+\frac{0.62 e^{\frac{1}{2}} \operatorname{Pr}^{\frac{1}{3}}}{\left[1+\left(\frac{0.4}{P_{r}}\right)^{\frac{2}{3}}\right]^{\frac{1}{4}}}\left[1+\left(\frac{R e}{282,000}\right)^{\frac{5}{8}}\right]^{\frac{-4}{5}}$ & \\
\hline & $N u=0.037 \operatorname{Re}^{0.8} \operatorname{Pr}^{0.33}$ & \\
\hline \multicolumn{3}{|l|}{ Ports } \\
\hline \multirow[t]{3}{*}{ Shayler et al. [34] } & $N u=0.135 R e^{0.713}$ & \\
\hline & $N u=C R e^{a} \operatorname{Pr}^{b}$ & \\
\hline & $N u=C \operatorname{Re}^{a} \operatorname{Pr}^{b}$ & \\
\hline
\end{tabular}

\subsection{Wall to Wall Heat Transfer}

The wall to wall heat transfer modelling is the approach for modelling heat transfer between engine parts, in the case of global and nodal models. It is also used to describe the heat transfer inside one specific engine part, for nodal and multidimensional models. This approach deals with conduction and contact resistance problems.

Borman and Nishiwaki didn't mentioned any of those models. Other authors have published reviews about internal combustion engine heat transfer, like Finol and Robinson [25] and Romero, in his PhD thesis [26], but neither have mentioned this engine heat transfer modelling approach. So, this is the first time this approach is reviewed.

Global models resolve the total heat transfer through each engine part based on the lumped capacitance assumption. This may be a reasonable assumption if Biot number is much smaller than unit, which is not true for several applications. Multidimensional models, on the other hand, resolve heat transfer and temperature distribution at each engine part under modelling. The use of finite element method on a mesh implemented over each part makes it possible to solve the transient heat diffusion equation for 2 or 3 dimensional problems. This solution is the most complete one, although it implies a great increase in computational time.

Nodal models are an intermediate solution for this tradeoff between accuracy of solution and computational cost. They also use the lumped capacitance assumption, but for the several nodes inside each engine part, instead of one complete part. This division makes it possible to solve a number of nodes much smaller than multidimensional ones, thus reducing computational cost. Nevertheless, it provides results of temperature distribution for few points at each part, and makes it more feasible to accomplish Biot number restriction for lumped capacitance assumption.

\subsubsection{Global Models for Wall to Wall Engine Heat Transfer}

Concise heat transfer and wall temperature models, similar to the one in Fig. 2, can be accomplished through the assumption that the Biot number is much smaller than unit for the evaluated engine parts. The simplified model can be used to estimate engine part temperature and heat transfer,

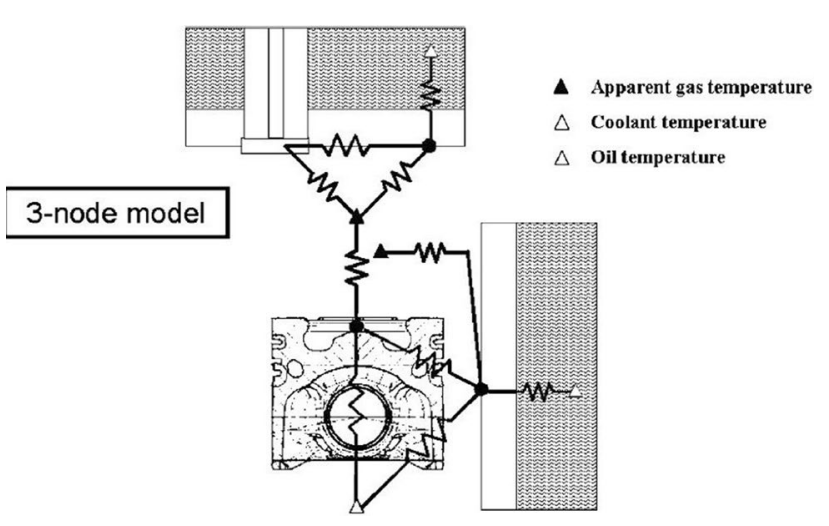

Fig. 2 Example of global heat transfer and wall temperature model proposed by Torregrosa et al. [44] 
although there is only one temperature value for each part, which is the main drawback for global models.

Baker and Assanis [45] developed a thermal resistance model to be used coupled to a thermodynamic model of a diesel engine. The authors used a 1D thermal resistance network to obtain boundary conditions to a finite element model of the cylinder liner and piston. The results of the FEM were used to calculate a $2 \mathrm{D}$ thermal resistance model. The values calculated for thermal resistances were cycle averaged ones, and only three nodes were present in this model, so any engine part would have a single node for temperature calculation.

Torregrosa et al. [44] developed a concise thermal resistance model for wall temperature prediction in diesel engines with piston cooling. The authors developed a three nodes model to calculate the heat flux from the hot gases inside the cylinder, until the lubricating oil and coolant, modeling the thermal conductance's between the three nodes and the boundary conditions.

The wall to wall heat transfer has been presented by the authors as follows:

$K_{\text {lin-cool }}=\left(\frac{\ln \left(\frac{D+2 \cdot e_{\text {lin }}}{D}\right)}{2 \cdot \pi \cdot S \cdot k_{A l}}+\frac{1}{A_{\text {lin, ext }} \cdot h_{\text {lin-cool }}}\right)^{-1}$
$K_{\text {pis-lin }}=\left(\frac{\ln \left(\frac{D}{0.5 D}\right)}{2 \cdot \pi \cdot h_{p c} \cdot k_{A l}}+\frac{1}{\pi \cdot D \cdot h_{p c} \cdot h_{p i s-l i n}}\right)^{-1}$

$K_{\text {head-cool }}=\left(\frac{e_{\text {head }}}{k_{A l} A_{\text {head }}}+\frac{1}{h_{\text {head-cool }}\left(A_{\text {head }}+A_{\text {run }}\right)}\right)^{-1}$

For each of the above expressions, the wall to wall heat transfer is modeled as thermal contact resistance, in cartesian and cylindrical coordinates.

The model has been validate against measurements in two diesel engines with 1,6 and 2,2 $\mathrm{L}$ displacement. One of the engines was equipped with 23 thermocouples $\mathrm{K}$ type in the cylinder liner, 16 thermocouples $\mathrm{K}$ type in the head. The other was equiped with 22 thermocouples in cylinder liner and 18 thermocouples in cilinder head.

\subsubsection{Nodal Models for Wall to Wall Engine Heat Transfer}

The division of engine parts into small number of nodes, illustrated in Fig. 3, makes nodal models more complete than global ones. Along with it, the use of the lumped capacitance assumption makes nodal models more versatile than multidimensional ones, once the computational cost is

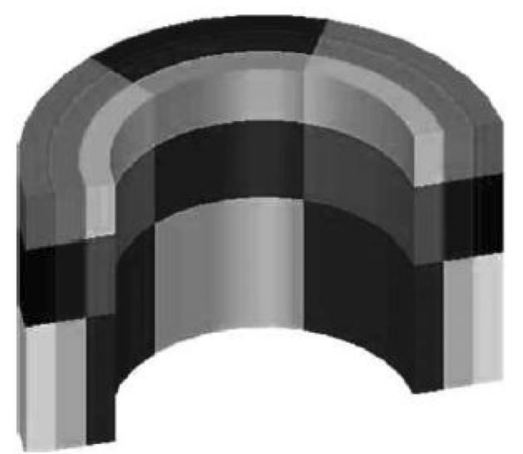

Fig. 3 Example of nodal division for cylinder liner heat transfer and wall temperature modelling proposed by Torregrosa et al. [46]

considerably reduced. The thermal nodes are connected by a network of heat transfer elements, which can be treated as thermal resistances or thermal conductance's.

Shayler et al. [47] published a thermal network analysis of a single cylinder engine, using a lumped capacitance model for considering a thermal network inside a $1.1 \mathrm{~L}$ single cylinder engine. The authors proposed a 23 nodes model including engine head, cylinder liner, cylinder block and piston, solving the transient discrete form of the diffusion equation for the 23 nodes group. The gases inside combustion chamber, lubricating oil and coolant was used as boundary conditions for this model.

Bohac et al. [8] developed a global model for characterization of thermal behaviour of engine parts inside an internal combustion engine. The authors used a lumped capacitance, lumped resistance model to describe the heat flux through a $1.9 \mathrm{~L} 4$ cylinder production engine, in transient operation. Along with thermal capacitance, described for all nodes considering only the mass and specify heat of the node, the authors described thermal resistances for the following phenomena: axial conduction, radial conduction, convection, radiation (linearized), in flow and out flow.

$R=\frac{L}{k A}$

$R=\frac{\ln \left(\frac{r_{2}}{r_{1}}\right)}{2 \pi H k}$

$R=\frac{1}{h A_{s}}$

$R=\frac{T_{2}-T_{1}}{\epsilon \sigma F_{21} A_{s}\left(T_{2}^{4}-T_{1}^{4}\right)}$

$R=\frac{1}{m_{\text {in }} c_{p, i n}}$ 


$$
R=\frac{1}{m_{\text {out }} c_{p, \text { out }}}
$$

The authors described a model that took into account heat transfer inside the cylinder, intake and exhaust ports, exhaust manifold and radiation shield, cylinder head, liner, piston, valves, coolant and oil ducts inside head and block, along with heat exchangers for coolant and oil. The coolant was a 50/50 mixture of ethylene glycol and water. The authors take several conclusions, among which can be highlighted: combustion must be modeled accurately in order to predict engine heat fluxes and temperatures; nucleate boiling is a very efficient heat transfer mechanism, and is essential if wall temperatures must be modeled accurately.

Jarrier et al. [48] performed the comparison between experimental and numerical values for a DI diesel engine during warm up. For the numerical values, the authors used a 53 nodes model representing metallic masses, coolant, oil and gases. The nodes are connected by thermal conductance's for conduction, convection, radiation, fluid flow, and each node may have thermal capacitance. The authors use heat source from combustion gases and from friction inside the cylinder, meanwhile the heat sinks are lubricating oil and coolant.

$$
\begin{aligned}
& G=\frac{k A}{d} \\
& G=h A \\
& G=\sigma \epsilon_{1} \epsilon 2 F_{1 / 2} A_{s}\left(T_{1}^{2}+T_{2}^{2}\right)\left(T_{1}+T_{2}\right) \\
& G=\dot{m} C_{p} \\
& M C_{p}
\end{aligned}
$$

Torregrosa et al. [46] presented a nodal model for estimation and calculation of diesel engine wall temperature. The model presented had 95 nodes for cylinder liner, piston and cylinder head, along with 5 nodes for fluid boundary conditions. The thermal model included thermal capacitance of each node, and also thermal resistances connecting neighbour nodes. The boundary conditions are the hot gases inside the cylinder as a hot sink, and the lubricating oil and coolant as heat sinks.

$$
\begin{gathered}
C_{i} \frac{T_{t+\Delta t}^{i}-T_{t}^{i}}{\Delta t}=\sum_{j} K_{i j}\left(T_{t+\Delta t}^{j}-T_{t+\Delta t}^{i}\right) \\
+\sum_{k} Q_{k \rightarrow i}+\sum_{l}\left(T^{l}-T_{t+\Delta t}^{i}\right) \\
K_{i j}=\frac{k A_{i j}}{d_{i j}}
\end{gathered}
$$

$K_{l i}=h_{l i} A_{l i}$

$$
C_{i}=m_{i} c_{v}
$$

\subsubsection{Multidimensional Models for Wall to Wall Engine Heat Transfer}

The multidimensional analysis for heat transfer inside engine parts is performed by the solution of the heat diffusion equation:

$\nabla(k \Delta T)=\rho c_{p} \frac{\partial T}{\partial t}$

Different options for the solution of this equations are used in the literature, with the main objective to calculate temperature distribution and heat fluxes through engine parts.

Baker and Assanis [45] used an axisymmetric 2D finiteelement model to resolve the heat flux through the combustion chamber components of a reciprocating engine. The transient heat conduction equation has been solved for a 2D axisymmetric domain, using a Fortran code, in such ways each component temperature is resolved separately during each time step. This model was coupled to a OD thermodynamic model, using heat transfer correlations as boundary conditions for heat transfer between combustion chamber parts and combustion gases, lubricating oil and coolant liquid. The results for the finite element models show piston temperatures around $900^{\circ} \mathrm{C}$ varying in space and time, cylinder liner temperature difference greater than $100^{\circ} \mathrm{C}$ from its top to a distance $10 \mathrm{~mm}$ below cylinder head. The results for heat transfer show peak heat transfer to the piston crown around $20 \mathrm{~kW}$, and peak heat transfer to cylinder liner around $40 \mathrm{~kW}$. The authors also discussed the coupling of this $2 \mathrm{D}$ heat transfer model to a OD thermodynamic model, and the possible coupling to an engine CFD model, in order to obtain spatially as well as temporally resolved gas boundary conditions.

Jafari and Hannani [49] performed an iterative analysis between KIVA II CFD 3D code and a finite element heat conduction code, in order to estimate the effect of fuel and engine operating characteristics on engine heat losses. The authors used an axisymmetric finite element model in order to calculate the heat flux from the in cylinder gases to the coolant. No specific modelling is presented for the heat transfer to the oil, or water, just wall temperatures are used for most of the surfaces boundary conditions.

Trujillo et al. [50] presented a methodology for estimation of cylinder inner surface temperature, using a finite element model. The engine used is a single cylinder, air cooled, direct injection diesel engine. The finite element model is applied to the cylinder heat transfer, meanwhile the in cylinder gas temperature and the cooling air temperature and heat transfer coefficient are the boundary conditions applied. For 
the heat supplied by the in cylinder gas, the authors used a heat flux distribution in order to model the effect of the heat transfer from the gases to the cylinder walls, thus it wasn't used any thermodynamic model.

Trujillo et al. [51] presented a methodology for estimation of head inner surface temperature, using a finite element model. The methodology is similar to the one presented at [50], in such a manner that the engine used is the same single cylinder, air cooled, direct injection diesel engine. A finite element model is used to resolve the heat flux through the head of the engine, with boundary conditions considered as the heat flux from the gases inside the cylinder, from the intake and exhaust gas fluxes, and also the cooling air flux. Once again no thermodynamic model is used to calculate the heat rejected from the in cylinder gases to the cylinder head, and the authors use a heat flux distribution to model this heat source.

Cerit and Coban [52] published a finite element analysis of temperature and thermal stresses analyses of a ceramiccoated aluminum alloy piston used in a diesel engine. The authors used finite element analysis, with heat transfer coefficient used as boundary conditions, in order to model heat transfer from gases to piston surface.

Lu et al. [53] presented a finite element analysis of thermal stress analysis on a piston engine, using a commercial finite element code. The authors used different heat transfer coefficient for great quantity of piston surfaces, and used a correction methodology for boundary conditions using experimental measured temperature values.

\subsubsection{Other Wall to Wall Heat Transfer Models}

Goudarzi et al. [54] presented an application of artificial neural networks in the estimation of exhaust valve temperature and thermal contact conductance in an internal combustion engine. The authors presented a transient set of equations to solve the problem of intermittent heat transfer between exhaust valve and valve seat, considering the only way to remove heat from exhaust valve is the valve seat contact. The set of equations solves a transient heat transfer problem, with a transient heat flux equation applied as boundary conditions, to calculate transient heat flux coefficient in valve contact, and also valve temperature. The authors concluded that the artificial neural network can estimate well the contact conductance coefficient and exhaust valve temperature. The authors present the results of training the neural networks, and conclude that exhaust valve temperature and contact conductance coefficient can be estimated well with the neural networks algorithm presented, although no validation procedure has been presented.

\subsubsection{Summarize Wall to Wall Heat Transfer}

Tables 3 and 4 summarize wall to wall heat transfer correlations, specially those used by nodal models.

The selection of each option for wall to wall heat transfer approach depends on the trade off between accuracy and resolution of the results and computational demand generated by the set of equations and boundary conditions. For applications where fast response is mandatory, global heat transfer models are the only options, and this way they must be calibrated for each application. On the other hand, for applications where high resolution of temperature distribution is mandatory, FEM models are the only option, and the computational time for this model must be accounted on the planning time.

It is clear in this section the importance of lumped capacitance assumption, this way it is important to verify Biot number in the model results, in order to verify model validity and accuracy. Among the models shown in this review, nodal models have a reasonable trade-off between resolution of temperature distribution inside the engine and computational demand.

\subsection{Wall to Liquid Heat Transfer}

The wall to liquid heat transfer is the approach for modelling heat transfer between engine parts and cooling liquid. It is also the approach for modelling heat transfer between engine parts and lubricating oil. This heat transfer approach does not account for air cooled engines. Borman and Nishiwaki didn't mentioned this heat transfer modelling approach, on the other hand, Romero [26], on his $\mathrm{PhD}$ thesis, presented a review concerning heat transfer to the cooling liquid and lubricating oil. Once this is not the first time this subject is reviewed, in this section the main correlations for both heat transfer modelling to coolant and oil are presented.

Table 3 Wall to wall heat transfer correlation: global models

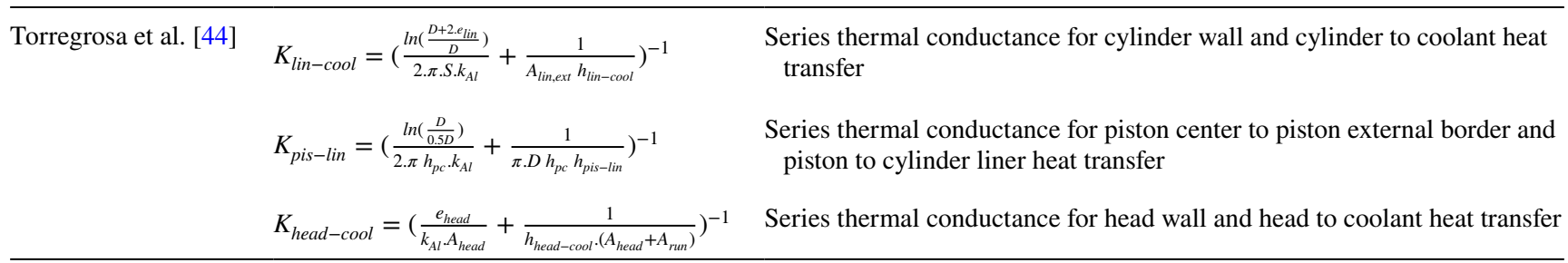


Table 4 Wall to wall heat transfer correlation: nodal models

\begin{tabular}{|c|c|c|}
\hline \multirow[t]{6}{*}{ Bohac et al. [8] } & $R=\frac{L}{k A}$ & $\begin{array}{l}\text { Thermal resistance for conduction nodes in Carte- } \\
\text { sian coordinates }\end{array}$ \\
\hline & $R=\frac{\ln \left(\frac{r_{2}}{r_{1}}\right)}{2 \pi H k}$ & $\begin{array}{l}\text { Thermal resistance for conduction nodes in cylin- } \\
\text { drical coordinates }\end{array}$ \\
\hline & $R=\frac{1}{h 4}$ & Thermal resistance for convection nodes \\
\hline & $R=\frac{T_{2}-T_{1}}{\epsilon \sigma F_{21} A_{s}\left(T_{2}^{4}-T_{1}^{4}\right)}$ & Thermal resistance for radiation nodes \\
\hline & 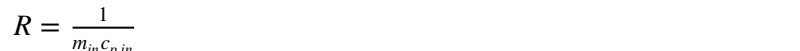 & Thermal resistance for intake flow nodes \\
\hline & $R=\frac{1}{m_{\text {out }} c_{\text {pout }}}$ & Thermal resistance for out flow nodes \\
\hline \multirow[t]{4}{*}{ Jarrier et al. [48] } & $G=\frac{k A}{d}$ & $\begin{array}{l}\text { Thermal conductance for conduction nodes in } \\
\text { Cartesian coordinates }\end{array}$ \\
\hline & $G=h A$ & Thermal conductance for convection nodes \\
\hline & $G=\sigma \epsilon_{1} \epsilon 2 F_{1 / 2} A_{s}\left(T_{1}^{2}+T_{2}^{2}\right)\left(T_{1}+T_{2}\right)$ & Thermal conductance for radiation nodes \\
\hline & $G=\dot{m} C_{p}$ & $\begin{array}{l}\text { Thermal conductance for intake and out flow } \\
\text { nodes }\end{array}$ \\
\hline Torregrosa et al. [46] & $\begin{array}{l}C_{i} \frac{T_{t+\Delta t}^{i}-T_{t}^{i}}{\Delta t}=\sum_{j} K_{i j}\left(T_{t+\Delta t}^{j}-T_{t+\Delta t}^{i}\right)+\sum_{k} Q_{k \rightarrow i}+\sum_{i l} K_{i l}\left(T^{l}-T_{t+\Delta t}^{i}\right) \\
\quad \text { where } K_{i j}=\frac{k A_{i j}}{d_{i j}} ; K_{l i}=h_{l i} A_{l i} ; C_{i}=m_{i} c_{v}\end{array}$ & $\begin{array}{l}\text { Thermal balance for each node of the model, } \\
\text { taking into account heat capacity, cartesian and } \\
\text { cylindrical conduction, convection }\end{array}$ \\
\hline
\end{tabular}

\subsubsection{Wall to Coolant Heat Transfer}

Wall to coolant heat transfer models generally use Nu-Re correlations for liquid turbulent flow. There are different configurations for the coolant galleries inside engine block and head, most of the coolant flow enters the block, flowing through the cylinders and head, and leaving the engine on the head. The heat transfer through the cylinders can be approximated as the flow through a bank of cylinders, although the heat transfer from the engine head to the coolant cannot. Whatever is the approach, nucleate boiling must be accounted for in the heat transfer coefficient estimation, once it is a very important heat transfer mechanism for both engine head and block.

Shayler et al. [47] used the method proposed by Finlay et al. [55], which employs Chen correlation [56] for nucleate boiling and Dittus-Boelter correlation for forced convection.

Bohac et al. [8] calculated a heat transfer coefficient $h$ between coolant gallery walls and coolant, by a sum of a convective heat trasnfer coefficient $h_{\text {conv }}$ using Grimson's Nusselt correlation for flow past a bank of cylinders, and a nucleate boiling heat transfer coefficient $h_{\text {nuc.boiling }}$ inside cooling galleries in contact with hot surfaces proposed by Chen [56].

$h=h_{\text {conv }}+h_{\text {nuc.boiling }}$

$N \bar{u}_{D}=1.13 C_{1} C_{2} \operatorname{Re}_{D}^{m} \operatorname{Pr}^{\frac{1}{3}}$

$h_{\text {nuc.boiling }}=0.0012\left(\frac{k_{f}^{0.79} c_{p, f}^{0.45} \rho_{p, f}^{0.49}}{\sigma^{0.5} \mu_{\phi}^{0.29}\left(\Delta h \rho^{0.24}\right)}\right) F$
Torregrosa et al. [44] developed correlations for thermal conductance between cylinder liner and water (27), and also for cylinder head and water (28), using thermal resistance theory. For the cylinder liner, the authors considered a series thermal circuit between conduction through cylinder liner wall and convection from cylinder to coolant, in such a manner the convective coefficient has been obtained experimentally. For the cylinder head, the authors considered a series thermal circuit between conduction through cylinder head wall and convection from head to coolant, in such a manner the convective coefficient has been adjusted from experimental data.

Torregrosa et al. [46] used a modified Dittus-Boelter correlation for calculation of the heat transfer coefficient between liner and coolant, and also for heat transfer between head and coolant.

$N \bar{u}_{D}=0.023 \operatorname{Re}_{D}^{0.8} \operatorname{Pr}^{0.4}$

The cooling system has been optimized in past decades by, among other strategies, subcooled boiling heat transfer strategies. This optimization lead to numerous benefits including reduced fuel consumption, lower emissions, increased power output and improved vehicle cabin comfort [57, 58]. The application of subcooled boiling heat transfer concept to internal combustion engine cooling is the subject of some investigation in literature [57, 59-61], and there is also some review on this subject $[58,62]$.

Li et al. [63] proposed a modified model with adjustable parameters for subcooled boiling heat transfer applications in CFD 3D codes. Several modifications are proposed by the authors on the basic equations in order to adapt them to CFD 
$3 \mathrm{D}$ analysis in geometrically complex cooling galleries of IC engines. Once these equations are specific to CFD 3D applications, they won't be described here for sake of brevity.

Torregrosa et al. [64] performed experiments on a heated duct to asses the validity of a Chen-type heat transfer correlation for subcooled flow boiling applications in internal combustion engines. The correlation proposed by Chen [56] (50) is used to calculate the total heat flux $q_{w}$ as:

$q_{w}=q_{f c}+q_{n b}=\Phi q_{f c}+S q_{n b}$

Here, $q_{f c}$ stands for the forced convection and $q_{n b}$ for the nucleate boiling heat fluxes, which are calculated, respectively by (51) and (52):

$q_{f c}=h_{f c}\left(T_{w}-T_{b}\right)$

$\tilde{q}_{n b}=h_{n b}\left(T_{w}-T_{s}\right)$

where $T_{w}$ is the wall temperature, $T_{b}$ is the bulk fluid temperature and $T_{s}$ is the saturation temperature. The heat transfer coefficient for forced convection, $q_{f c}$, is computed using a Dittus-Boelter equation modified by Robinson et al.

$h_{f c}=0.023 \operatorname{Re}_{l}^{0.8} \operatorname{Pr}_{l}^{0.4}\left(\frac{\mu_{b}}{\mu_{w}}\right)^{0.14}\left(\frac{k_{l}}{D_{h}}\right)$

where $k_{l}$ is the thermal conductivity of the liquid phase, $D_{h}$ is the hydraulic diameter, $\mu_{b}$ and $\mu_{w}$ are the dynamic viscosity evaluated at the wall and bulk temperatures, respectively, and $R e_{l}$ and $P r_{l}$ are the Reynols and Prandtl numbers for the liquid phase:

$R e_{l}=\frac{\rho_{l} u_{b} D_{h}}{\mu l}, \operatorname{Pr}_{l}=\frac{\mu_{l} c_{p, l}}{k_{l}}$

where $u_{b}$ is the bulk flow velocity and $c_{p, l}, \rho_{l}$ and $\mu_{l}$ are the specific heat, density dynamic viscosity of the fluid, respectively, evaluated at its bulk temperature.

The heat transfer coefficient for nucleate boiling, $h_{n b}$, is calculated using a correlation proposed by Forster and Zuber for pool boiling heat transfer:

$h_{n b}=0.00122 \frac{k_{l}^{0.79} c_{p, l}^{0.45} \rho_{l}^{0.49}}{\sigma^{0.5} \mu_{l}^{0.29} l_{l g}^{0.24} \rho_{g}^{0.24}} \Delta T_{s}^{0.25} \Delta p_{s}^{0.25}$

where $l_{l g}$ is the latent heat of vaporization, $\sigma$ is the surface tension, $\rho_{g}$ is the density of the vapour phase, $\Delta T_{s}=T_{w}-T_{s}$ is the wall superheat and $\Delta p=p_{s}\left(T_{w}\right)-p_{s}\left(T_{s}\right)$ is the corresponding saturation pressure difference.

(50) is modified by the parameters $\Phi$ and $F$, where the first one is a correction factor accounting for the influence of microconvective effects associated with bubble agitation:

$\Phi=\left(\frac{P r_{l}+1}{2}\right)^{0.444} F>1$
Factor $F$ is and enhancement factor related to the ratio of the two-phase Reynolds number $R e_{2 \Phi}$ and the liquid phase Reynolds number $R e_{l}$.

$F=\left(\frac{R e_{2 \Phi}}{R e_{l}}\right)^{0.8}$

In (50), factor $S$ stands for the suppression factor, which accounts for the observed decrease in nucleate boiling activity when the flow velocity increases, and is evaluated by:

$S=\frac{1}{1+2.53 \times 10^{-6} R e_{2 \Phi}^{1.17}}<1$

The authors noticed from the results obtained that the reference model were in good agreement with experiment for wall temperatures below $135^{\circ} \mathrm{C}$, and above this value of wall temperature there was a considerable discrepancy. They proposed an adjustment parameter $\Psi$, so the modified equation for the suppression factor $S$ is:

$S=\Psi \frac{1}{1+2.53 \times 10^{-6} \operatorname{Re}_{2 \Phi}^{1.17}}<1$

The adjustment parameter $\Psi$ was evaluated as a function of Prandtl number, and is proposed as [64]:

$\Psi=0.104 P r_{l}-0.4$

The authors concluded that for wall temperatures below $135^{\circ} \mathrm{C}$, the reference correlation is in good agreement with experimental measurements. For temperatures above that value, they proposed the adjustment parameter $\Psi$ for the suppression factor, as a function of the Prandtl number.

Mehdipour et al. [65] presented a CFD 3D simulation of water flow inside a conventional channel, taking into account boiling and bubble flow into a mixture flow two phase model, in order to represent flow inside the channels of an internal combustion chamber.

Modeling adequately heat transfer from engine walls to coolant is an important task in order to quantify the heat losses properly. Current trends at engine design are at using each time more intensively nucleate boiling and subcooled boiling heat transfer as strategies to reduce heat losses and maintain engine temperature under control. This way, wall to coolant heat transfer models must take into account subcooled boiling along with convective heat transfer and low coolant mass flow rate in order to predict adequately coolant system performance parameters and wall temperatures.

\subsubsection{Wall to Oil Heat Transfer}

Wall to oil heat transfer is the only cooling option for piston, along with its lubricating function. This way, the correct wall to oil heat transfer modelling is mandatory for piston temperature estimation. 
Bohac et al. [8] used literature values for the convective heat transfer coefficient between oil and piston, in such a manner that different piston cooling strategies (splash, forced or jet) would have different heat transfer coefficient ranges. Once the coefficient was measured in an specific engine speed, an equation for correction of the convective coefficient concerning engine speed effect is proposed. The authors do not mention any correlation for heat transfer between cylinder liner and oil.

Torregrosa et al. [44] developed correlations for the thermal conductance between piston and oil and liner and oil, adjusting the proposed correlations based on experimental results in two diesel engines. For the conductance between piston and oil $K_{\text {pis-oil }}$, the authors concluded it is a function of engine speed, and the proposed correlation takes it into account by the mean piston speed.

$K_{\text {pis-oil }}=\pi^{2} \cdot D_{\text {gal }} \cdot\left(d_{\text {gal }}\right)^{m} \cdot C_{g a l}^{\prime} \cdot\left(S_{p}\right)^{m}$

where $D_{g a l}$ is the diameter of the oil gallery built into the piston, $d_{g a l}$ is the internal diameter of the oil gallery, similar to the diameter of the piston, $m=0.73$ is the exponent adjusted by experimental values.

On the other hand, the authors modeled the conductance between liner and oil using a standard convective correlation, and adjusted the convective coefficient to fit the experimental data.

$K_{\text {lin-oil }}=\pi \cdot D \cdot S \cdot h_{\text {lin-oil }}$

where $\mathrm{D}$ and $\mathrm{S}$ are cylinder bore and stroke, respectively, and $h_{\text {lin-oil }}=870 \frac{\mathrm{W}}{\mathrm{m}^{2} K}$ is adjusted by experimental values.

The authors concluded, after fitting the model and adjusting its constants, that the conductance between piston and oil depends on piston speed, all of the other conductance's evaluated has shown to be constant.

Torregrosa et al. [46] used the same correlations as described by Torregrosa et al. [44] in order to model heat transfer between piston and oil, and also cylinder liner and oil.

Torregrosa et al. [66] proposed a correlation for the film coefficient related to the convective heat transfer through the oil gallery in a real life piston geometry of a Diesel automotive engine. The authors used a test bench composed of two oil circuits: one for oil heated until $300^{\circ} \mathrm{C}$ by electrical resistances, used to heat piston surface; another one for oil at temperatures below $100^{\circ} \mathrm{C}$ with a system to control temperature, used to cool down the piston. Piston temperature is measured by thermal resistances at 6 points, and the piston is divided in 12 nodes, using the 6 measured points and a lumped capacitance model to calculate the temperature of the nodes which doesn't have a thermal resistance.

The results obtained for the Nusselt number showed a dependence on the piston position during the cycle, and also on the regime of the cooling oil flow. The correlation proposed for the cycle average Nusselt number $\overline{\mathrm{Nu}}$ is in the form of (63):
$\overline{N u}=\frac{1}{4 \pi} \int_{0}^{4 \pi}\left[a \operatorname{Re}^{b} \operatorname{Pr}^{c}\right] d \alpha$

where Re and Pr are Reynolds and Prandtl number, respectively, and $a, b$ and $c$ are constants adjusted for each piston position. The values for those constants are available at [66] for different piston position and oil flow regime.

Liu et al. [67] developed an area-average heat transfer correlation to be employed for numerical evaluation of oiljet cooling of pistons inside internal combustion engines.

$N u_{\text {avg }}=13.932 R_{e, O}^{0.596} \operatorname{Pr}^{0.239}\left(\frac{Z}{d_{0}}\right)^{0.089}\left(\frac{D}{d_{0}}\right)^{-1.398}\left(\frac{\mu_{w}}{\mu_{a w}}\right)_{(64)}^{0.312}$

The authors conducted a series of experiments on a production engine piston, using thermal resistances and insulation system, associated with an oil jet nozzle and an oil circuit, in order to represent different engine operation conditions. The authors adjusted a Nu-Re correlation, based on the nozzle exit diameter, to fit all of the data obtained.

Peng et al. [68] used a CFD 3D model for the oil gallery, coupled to a finite element model of the piston, to calculate the flow and heat transfer of nanofluids inside the oil gallery of a diesel engine piston. The nanofluid used is a mixture of oil with copper and diamond particles. The nanofluid flow is simulated using a volume of fluid analysis, to take into account the fraction of oil gallery not filled by oil due to the mechanism of filling this gallery.

\subsubsection{Summarize Wall to Liquid Heat Transfer}

Table 5 summarizes wall to coolant and wall to oil heat transfer.

\subsection{Wall Temperature Calculation}

The temperature calculation of surfaces inside internal combustion engines is the main purpose for using different heat transfer models coupled. Several papers in literature presents wall temperature calculation, some of them present calculation of wall temperature for different surfaces, meanwhile other ones present specific engine parts wall temperature calculation.

Table 5 Wall to liquid heat transfer

\begin{tabular}{lll}
\hline Author & Equation & Observation \\
\hline Coolant heat transfer & \\
Bohac et al. [8] & $h=h_{\text {conv }}+h_{\text {nuc.boiling }}$ \\
& $N \bar{u}_{D}=1.13 C_{1} C_{2} \operatorname{Re}_{D}^{m} \operatorname{Pr}^{\frac{1}{3}}$ \\
& $h_{\text {nuc.boiling }}=0.0012\left(\frac{k_{f}^{0.79} c_{p . f}^{0.45} \rho_{p . f}^{0.49}}{\sigma^{0.5} \mu_{\phi}^{0.29}\left(\Delta h \rho^{0.24}\right)}\right) F$
\end{tabular}


Torregrosa et al. [46] presented a nodal model for wall temperature calculation of the surfaces inside combustion chamber, at the valves and ports of a single cylinder, diesel engine. The model uses the lumped capacitance assumption for a series of nodes inside cylinder head, ports, cylinder liner and piston, in order to resolve heat transfer equation for all of the nodes. The model is validated using a series of thermocouples installed in the cylinder and head of the engine, in order to evaluate the temperature distribution calculated by the model.

Payri et al. [69] presented a global energy balance model, in order to provide real time information about engine wall temperature for experimental engine investigations. The model uses experimental data measured in a 4 cylinder DI diesel engine, 1 valve per cylinder, 1,6 $\mathrm{L}$ displaced volume, in order to measure several quantities and perform an external global energy balance. For the internal global energy balance, the authors used several models for heat transfer between gases and walls for cylinder and ports, heat transfer inside each engine part, heat transfer to oil and coolant, heat transfer to turbocharger, and several other heat fluxes that occur during engine operation.

Cerdoun et al. [33] performed the calculation of exhaust valve temperature distribution using a group of models for estimate heat transfer coefficients over several valve surface regions. For valve face, Woschni correlation was used once this face is in contact with in cylinder gases. For valve seat, three heat transfer correlations are used in a similar manner to the one used to describe mass flow through the valve during open valve time, and thermal contact resistance is used during closed valve time. The valve temperature distribution is calculated using finite element model.

Lu et al. [53] performed a finite element analysis for calculation of steady state and transient temperature distribution in a diesel engine piston, along with thermal stresses. The authors used a great quantity of boundary conditions for heat transfer on different regions of piston surface, from different positions of piston bowl until valve rings, passing through oil galleries. The calculation of the authors is restricted to piston temperatures, and there is no thermodynamic model considered, once the thermodynamic process is represented by the boundary conditions over piston surface.

There are several papers in literature presenting wall temperature calculation, most of them present the calculation of the wall temperature without coupling the heat transfer models to a thermodynamic one, should it be a zero dimensional, multizone or multidimensional one.

\subsection{CHT-Conjugate Heat Transfer}

The use of coupled thermodynamic and heat transfer models, in order to predict simultaneously engine behaviour and surface temperature, is also named CHT-Conjugated Heat Transfer.

Kikusato et al. [70] performed a conjugate heat transfer analysis between a CFD 3D engine thermodynamic code and a finite volume model for heat transfer calculation between in cylinder gases and coolant. In this model, a closed cycle analysis in a single cylinder diesel engine is performed for the thermodynamic point of view, using KIVA II CFD 3D code, coupled to a chemical kinetics program to solve combustion and a one dimensional transient heat transfer model.

For the wall heat transfer, a one dimensional transient finite volume heat transfer model is used. The heat transfer between gases and walls is resolved using a law-of-the-wall model, and the heat transfer from walls to coolant is calculated using a modified Dittus-Boelter correlation for the cylinder and liner, where there is coolant flow. For the piston, the Woschni correlation is used to calculate the coolant side heat transfer coefficient, which is a procedure substantially different than used by most authors in literature.

The authors presented validation of the model, comparing in cylinder pressure, heat release rate, and cylinder head wall temperature surface traces for $1200 \mathrm{rpm}$, at $25 \%$ and $50 \%$ load. The pressure, heat release and wall surface temperature traces are in good agreement for the cases presented as validation.

The authors presented results for distribution of wall surface temperature, heat flux and heat transfer coefficient. The changes in wall temperatures locally affects heat fluxes and increases heat losses, such as those presented for regions where wall impingement occurred and squish flow regions. As a conclusion, the authors state that wall impingement must be avoided, in order to reduce heat losses and increase thermal efficiency.

Martín et al. [71] performed a conjugate heat transfer analysis, using a 0D thermodynamic model coupled to a nodal lumped capacitance heat transfer model, in order to perform thermal analysis of a diesel engine operating with diesel gasoline dual fuel combustion mode under a reactivity controlled compression ignition approach.

Zhang [15] performed a conjugate heat transfer analysis in a closed cycle simulation of a DI diesel engine. The CFD-3D code KIVA-4V was used to solve the equations for conservation of mass, momentum and energy, coupled to several models for turbulence, combustion, spray, etc. The equations of the CFD-3D code was also used to solve the heat flux through the solid phase, concerning cylinder head, cylinder liner and piston top.

Benajes et al. [18] performed a conjugate heat transfer analysis, using a 0D thermodynamic model coupled to a nodal lumped capacitance heat transfer model, in order to evaluate the effect of swirl ratio on the global energy balance of a high speed direct injection diesel engine. The authors performed experiments in a 4 cylinder, turbocharged diesel 
engine, in order to perform external global energy balance, and used the coupled thermodynamic and heat transfer models to evaluate the internal global energy balance.

Broatch et al. [72] proposed an alternative methodology to perform conjugate heat transfer at engine CFD 3D simulations, instead of solving full fluid and solid domains during several engine cycles. The authors propose to perform a previous simulation of the combustion process using constant wall temperature as boundary conditions, followed by a simulation of the heat transfer process using the rate of heat release obtained from the combustion process as boundary condition. The authors use CONVERGE CFD to perform both full fluid and solid coupled simulations, and also decoupled combustion and rate of heat release simulation. The results obtained by the authors using both methodologies are in good agreement with GT Power data for the engine evaluated, and the authors induced that a reduction between 38 and $50 \%$ by engine cycle was gained.

Many authors present CHT analysis involving CFD 3D engine simulations, although every engine model where thermodynamic and heat transfer are coupled to obtain a solution that satisfy both conditions is a CHT model.

\section{Summary}

A review about internal combustion engine heat transfer and wall temperature modelling is presented in this paper. Three heat transfer approaches are considered for this review: gas to wall, wall to wall and wall to liquid heat transfer.

For gas to wall heat transfer approach, the evaluation of most widely used correlation is presented. The literature reviewed agree that traditional correlation predictions for total heat flux are in good agreement with experiments, but lacks in accuracy on instantaneous heat fluxes. New correlations are presented for specific cases, like high tumble engines or specific fuel engines like hydrogen ones. The new correlations are based on traditional ones, and show better performance when compared to experimental results.

For wall to wall heat transfer approach, which is reviewed for the first time, global models, nodal models and finite element models are discussed. The best trade off between computational cost and temperature distribution is obtained by nodal models, which also makes it more profitable to attend to Biot number restriction for lumped capacitance assumption. It can be concluded by this review that the most indicated models to use accomplished to engine thermodynamic models are global and nodal models, for applications which thermodynamic results are the main purpose.

For wall to liquid heat transfer approach, which is reviewed for the first time in a paper, literature agree that heat transfer from engine to liquid coolant should be calculated by both convective and buoyancy correlations, due to local flash buoyancy occurrence close to combustion chamber both in engine head and block. Also, correlations for heat transfer between lubricating oil and engine parts, like cylinder liner and piston, are reviewed.

The use of all those correlations for different heat transfer approaches are required for engine wall temperature calculation for any specific application, but specially for CHT analysis coupled to phenomenological or multidimensional thermodynamic models.

Acknowledgements The author Leonardo Fonseca acknowledges CAPES (Coordination for the Improvement of Higher Education Personnel) for the scholarship from the program "CAPES - DEMANDA SOCIAL", PhD level.

Funding This study was partially funded by "CAPES - DEMANDA SOCIAL" Ph.D. level scholarship, from CAPES (Coordination for the Improvement of Higher Education Personnel).

\section{Compliance with Ethical Standards}

Conflict of interest The authors declare that they have no conflict of interest.

\section{References}

1. Olmeda P, Martín J, Novella R, Carreño R (2015) An adapted heat transfer model for engines with tumble motion. Appl Energy 158:190-202. https://doi.org/10.1016/j.apenergy.2015.08.051

2. Broekaert S, Demuynck J, De Cuyper T, De Paepe M, Verhelst Sebastian (2016) Heat transfer in premixed spark ignition engines part i: identification of the factors influencing heat transfer. Energy 116:380-391. https://doi.org/10.1016/j.energy.2016.08.065

3. Kosmadakis GM, Pariotis EG, Rakopoulos CD (2013) Heat transfer and crevice flow in a hydrogen-fueled spark-ignition engine: effect on the engine performance and no exhaust emissions. Int J Hydrog Energy 38(18):7477-7489. https://doi.org/10.1016/j.ijhyd ene.2013.03.129

4. Borman G, Nishiwaki K (1987) Internal-combustion engine heat transfer. Prog Energy Combust Sci 13(1):1-46. https://doi. org/10.1016/0360-1285(87)90005-0

5. Yamakawa M, Youso T, Fujikawa T, Nishimoto T, Wada Y, Sato K, Yokohata H (2012) Combustion technology development for a high compression ratio SI engine. SAE Int J Fuels Lubr 5(1):98105. https://doi.org/10.4271/2011-01-1871

6. Deng B, Jianqin F, Zhang D, Yang J, Feng R, Liu J, Li K, Liu X (2013) The heat release analysis of bio-butanol/gasoline blends on a high speed SI (spark ignition) engine. Energy 60:230-241. https://doi.org/10.1016/j.energy.2013.07.055

7. Šarić S, Basara B, Žunič Z (2017) Advanced near-wall modeling for engine heat transfer. Int J Heat Fluid Flow 63:205-211. https ://doi.org/10.1016/j.ijheatfluidflow.2016.06.019

8. Bohac SV, Baker DM, Assanis DN (1996) A global model for steady state and transient SI engine heat transfer studies. Technical report, SAE Technical Paper. https://doi.org/10.4271/960073

9. Bürkle S, Biondo L, Ding C-P, Honza R, Ebert Volker, Böhm Benjamin, Wagner Steven (2018) In-cylinder temperature measurements in a motored ic engine using tdlas. Flow Turbul Combust 101(1):139-159. https://doi.org/10.1007/s10494-017-9886-y 
10. Kosmadakis GM, Pariotis EG, Rakoupoulos CD (2012) Comparative analysis of three simulation models applied on a motored internal combustion engine. Energy Convers Manag 60:45-55. https://doi.org/10.1016/j.enconman.2011.11.031

11. Bernard G, Lebas R, Demoulin F-X (2011) A Od phenomenological model using detailed tabulated chemistry methods to predict diesel combustion heat release and pollutant emissions. Technical report, SAE Technical Paper. https://doi. org/10.4271/2011-01-0847

12. Ge H-W, Shi Y, Reitz RD, Wickman DD, Willems Werner (2009) Optimization of a HSDI diesel engine for passenger cars using a multi-objective genetic algorithm and multi-dimensional modeling. SAE Int J Engines 2(1):691-713. https://doi. org/10.4271/2009-01-0715

13. Vancoillie J, Sileghem L, Verhelst S (2014) Development and validation of a quasi-dimensional model for methanol and ethanol fueled si engines. Appl Energy 132:412-425. https://doi. org/10.1016/j.apenergy.2014.07.046

14. Verhelst S, Sheppard CGW (2009) Multi-zone thermodynamic modelling of spark-ignition engine combustion-an overview. Energy Convers Manag 50(5):1326-1335. https://doi. org/10.1016/j.enconman.2009.01.002

15. Zhang L (2018) Parallel simulation of engine in-cylinder processes with conjugate heat transfer modeling. Appl Thermal Eng 142:232-240. https://doi.org/10.1016/j.appltherma leng.2018.06.084

16. Broatch A, Olmeda P, García A, Salvador-Iborra J, Warey A (2017) Impact of swirl on in-cylinder heat transfer in a light-duty diesel engine. Energy 119:1010-1023. https://doi.org/10.1016/j. energy.2016.11.040

17. Rashedul HK, Kalam MA, Masjuki HH, Ashraful AM, Imtenan S, Sajjad H, Wee LK (2014) Numerical study on convective heat transfer of a spark ignition engine fueled with bioethanol. Int Commun Heat Mass Transf 58:33-39. https://doi.org/10.1016/j. icheatmasstransfer.2014.08.019

18. Benajes J, Olmeda P, Martín J, Blanco-Cavero D, Warey Alok (2017) Evaluation of swirl effect on the global energy balance of a HSDI diesel engine. Energy 122:168-181. https://doi. org/10.1016/j.energy.2017.01.082

19. Weller HG, Uslu S, Gosman AD, Maly RR, Herweg R, Heel B (1994) Prediction of combustion in homogeneous-charge sparkignition engines. Int Symp COMODIA 94:163-169

20. Heywood John B (1994) Combustion and its modeling in sparkignition engines. In: International symposium COMODIA, vol 94, pp $1-15$

21. Reuss DL, Kuo T-W, Khalighi B, Haworth D, Rosalik M (1995) Particle image velocimetry measurements in a high-swirl engine used for evaluation of computational fluid dynamics calculations. Technical report, SAE Technical Paper. https://doi. org/10.4271/952381

22. Wang Z, Shuai S-J, Wang J-X, Tian G-H (2006) A computational study of direct injection gasoline hcci engine with secondary injection. Fuel 85(12-13):1831-1841. https://doi.org/10.1016/j. fuel.2006.02.013

23. Millo F, Luisi S, Borean F, Stroppiana A (2014) Numerical and experimental investigation on combustion characteristics of a spark ignition engine with an early intake valve closing load control. Fuel 121:298-310. https://doi.org/10.1016/j.fuel.2013.12.047

24. di Mare F, Knappstein R, Baumann M (2014) Application of lesquality criteria to internal combustion engine flows. Comput Fluids 89:200-213. https://doi.org/10.1016/j.compfluid.2013.11.003

25. Finol CA, Robinson K (2006) Thermal modelling of modern engines: a review of empirical correlations to estimate the incylinder heat transfer coefficient. Proc Inst Mech Eng Part D J Automob Eng 220(12):1765-1781. https://doi.org/10.1243/09544 070JAUTO202
26. Romero CA (2009) Contribución al conocimiento del comportamiento térmico y la gestión térmica de los motores de combustión interna alternativos. PhD thesis, Universitat Politècnica de València. https://doi.org/10.4995/Thesis/10251/4923

27. Fan X, Che Z, Wang T, Zhen L (2018) Numerical investigation of boundary layer flow and wall heat transfer in a gasoline directinjection engine. Int J Heat Mass Transf 120:1189-1199. https:// doi.org/10.1016/j.ijheatmasstransfer.2017.09.089

28. Ngang EA, Abbe CVN (2018) Experimental and numerical analysis of the performance of a diesel engine retrofitted to use LPG as secondary fuel. Appl Therm Eng 136:462-474. https://doi. org/10.1016/j.applthermaleng.2018.03.022

29. Soloiu V, Moncada JD, Gaubert R, Muiños M, Harp S, Ilie M, Zdanowicz A, Molina G (2018) LTC (low-temperature combustion) analysis of PCCI (premixed charge compression ignition) with n-butanol and cotton seed biodiesel versus combustion and emissions characteristics of their binary mixtures. Renew Energy 123:323-333. https://doi.org/10.1016/j.renene.2018.02.061

30. Renaud A, Ding C-P, Jakirlic S, Dreizler A, Böhm B (2018) Experimental characterization of the velocity boundary layer in a motored IC engine. Int J Heat Fluid Flow 71:366-377. https:// doi.org/10.1016/j.ijheatfluidflow.2018.04.014

31. Torregrosa AJ, Broatch A, Olmeda P, Salvador-Iborra J, Warey A (2017) Experimental study of the influence of exhaust gas recirculation on heat transfer in the firedeck of a direct injection diesel engine. Energy Convers Manag 153:304-312. https://doi. org/10.1016/j.enconman.2017.10.003

32. Ma PC, Ewan T, Jainski C, Lu L, Dreizler Andreas, Sick Volker, Ihme Matthias (2017) Development and analysis of wall models for internal combustion engine simulations using high-speed micro-piv measurements. Flow Turbul Combust 98(1):283-309. https://doi.org/10.1007/s10494-016-9734-5

33. Cerdoun M, Carcasci C, Ghenaiet A (2016) An approach for the thermal analysis of internal combustion engines' exhaust valves. Appl Ther Eng 102:1095-1108. https://doi.org/10.1016/j.applt hermaleng.2016.03.105

34. Shayler PJ, Colechin MJF, Scarisbrick A (1996) Heat transfer measurements in the intake port of a spark ignition engine. Technical report, SAE Technical Paper. https://doi.org/10.4271/96027 3

35. Luján JM, Climent H, Olmeda P, Jiménez VD (2014) Heat transfer modeling in exhaust systems of high-performance twostroke engines. Appl Therm Eng 69(1-2):96-104. https://doi. org/10.1016/j.applthermaleng.2014.04.045

36. Michl J, Neumann J, Rottengruber H, Wensing M (2016) Derivation and validation of a heat transfer model in a hydrogen combustion engine. Appl Therm Eng 98:502-512. https://doi. org/10.1016/j.applthermaleng.2015.12.062

37. Pischinger R, Klell M, Sams T (2009) Thermodynamik der Verbrennungskraftmaschine. Springer, Wien. https://doi. org/10.1007/978-3-211-99277-7

38. Annand WJD (1963) Heat transfer in the cylinders of reciprocating internal combustion engines. Proc Inst Mech Eng 177(1):973996. https://doi.org/10.1243/PIME_PROC_1963_177_069_02

39. Woschni G (1967) A universally applicable equation for the instantaneous heat transfer coefficient in the internal combustion engine. Technical report, SAE Technical paper. https://doi. org/10.4271/670931

40. Han SB, Chung YJ, Kwon YJ, Lee S (1997) Empirical formula for instantaneous heat transfer coefficient in spark ignition engine. Technical report, SAE Technical Paper. https://doi. org/10.4271/972995

41. De Cuyper T, Broekaert S, Chana K, De Paepe M, Verhelst S (2017) Evaluation of empirical heat transfer models using TFG heat flux sensors. Appl Therm Eng 118:561-569. https://doi. org/10.1016/j.applthermaleng.2017.02.049 
42. Irimescu A, Merola SS, Tornatore C, Valentino G (2015) Development of a semi-empirical convective heat transfer correlation based on thermodynamic and optical measurements in a spark ignition engine. Appl Energy 157:777-788. https://doi. org/10.1016/j.apenergy.2015.02.050

43. Martins JJG, Finlay IC (1990) Heat transfer to air-ethanol and air-methanol sprays flowing in heated ducts and across heated intake valves. Technical report, SAE Technical Paper. https://doi. org/10.4271/900583

44. Torregrosa AJ, Olmeda P, Degraeuwe B, Reyes M (2006) A concise wall temperature model for DI diesel engines. Appl Therm Eng 26(11-12):1320-1327. https://doi.org/10.1016/j.appltherma leng.2005.10.021

45. Baker DM, Assanis DN (1994) A methodology for coupled thermodynamic and heat transfer analysis of a diesel engine. Appl Math Modell 18:590-601. https://doi.org/10.1016/0307904X(94)90317-4

46. Torregrosa AJ, Olmeda P, Martín J, Romero C (2011) A tool for predicting the thermal performance of a diesel engine. Heat Transf Eng 32(10):891-904. https://doi.org/10.1080/01457 632.2011 .548639

47. Shayler PJ, Christian SJ, Ma T (1993) A model for the investigation of temperature, heat flow and friction characteristics during engine warm-up. Technical report, SAE Technical Paper. https:// doi.org/10.4271/931153

48. Jarrier L, Champoussin JC, Yu R, Gentile D (2000) Warm-up of a DI diesel engine: experiment and modeling. Technical report, SAE Technical Paper. https://doi.org/10.4271/2000-01-0299

49. Jafari A, Hannani SK (2006) Effect of fuel and engine operational characteristics on the heat loss from combustion chamber surfaces of SI engines. Int Commun Heat Mass Transf 33(1):122-134. https://doi.org/10.1016/j.icheatmasstransfer.2005.08.008

50. Trujillo EC, Jiménez-Espadafor FJ, Villanueva JAB, García MT (2011) Methodology for the estimation of cylinder inner surface temperature in an air-cooled engine. Appl Therm Eng 31:14741481. https://doi.org/10.1016/j.applthermaleng.2011.01.025

51. Trujillo EC, Jiménez-Espadafor FJ, Villanueva JAB, García MT (2012) Methodology for the estimation of head inner surface temperature in an air-cooled engine. Appl Therm Eng 35:202-211. https://doi.org/10.1016/j.applthermaleng.2011.10.032

52. Cerit M, Coban M (2014) Temperature and thermal stress analyses of a ceramic-coated aluminum alloy piston used in a diesel engine. Int J Therm Sci 77:11-18. https://doi.org/10.1016/j.ijthe rmalsci.2013.10.009

53. Yaohui L, Zhang X, Xiang P, Dong D (2017) Analysis of thermal temperature fields and thermal stress under steady temperature field of diesel engine piston. Appl Therm Eng 113:796-812. https ://doi.org/10.1016/j.applthermaleng.2016.11.070

54. Goudarzi K, Moosaei A, Gharaati M (2015) Applying artificial neural networks (ANN) to the estimation of thermal contact conductance in the exhaust valve of internal combustion engine. Appl Therm Eng 87:688-697. https://doi.org/10.1016/j.appltherma leng.2015.05.060

55. Finlay IC, Harris D, Boam DJ, Parks BI (1985) Factors influencing combustion chamber wall temperatures in a liquidcooled, automotive, spark-ignition engine. Proc Inst Mech Eng Part D Transp Eng 199(3):207-214. https://doi.org/10.1243/ PIME_PROC_1985_199_158_01

56. Chen JC (1966) Correlation for boiling heat transfer to saturated fluids in convective flow. Ind Eng Chem Process Des Dev 5(3):322-329. https://doi.org/10.1021/i260019a023

57. Robinson K, Hawley JG, Hammond GP, Owen NJ (2003a) Convective coolant heat transfer in internal combustion engines. Proc Inst Mech Eng Part D J Autom Eng 217(2):133-146. https://doi. org/10.1177/095440700321700207
58. Robinson K, Campbell NAF, Hawley JG, Tilley DG (1999) A review of precision engine cooling. Technical report, SAE Technical Paper. https://doi.org/10.4271/1999-01-0578

59. Kandlikar SG (1998) Heat transfer characteristics in partial boiling, fully developed boiling, and significant void flow regions of subcooled flow boiling. J Heat Transf 120(2):395-401. https://doi. org/10.1115/1.2824263

60. Robinson K, Hawley JG, Campbell NAF (2003b) Experimental and modelling aspects of flow boiling heat transfer for application to internal combustion engines. Proc Inst Mech Eng Part D J Autom Eng 217(10):877-889. https://doi.org/10.1243/095440703769683289

61. Kandlikar SG, Bulut M (2003) An experimental investigation on flow boiling of ethylene-glycol/water mixtures. J Heat Transf 125(2):317-325. https://doi.org/10.1115/1.1561816

62. Steiner H, Brenn G, Ramstorfer F, Breitschädel B (2011) Increased cooling power with nucleate boiling flow in automotive engine applications. In: Chiaberge M (ed) New trends and developments in automotive system engineering, chapter 13. IntechOpen, Rijeka

63. Li Z, Huang RH, Wang ZW (2012) Subcooled boiling heat transfer modelling for internal combustion engine applications. Proc Inst Mech Eng Part D J Autom Eng 226(3):301-311. https://doi. org/10.1177/0954407011417349

64. Torregrosa AJ, Broatch A, Olmeda P, Cornejo O (2014) Experiments on subcooled flow boiling in ic engine-like conditions at low flow velocities. Exp Therm Fluid Sci 52:347-354. https://doi. org/10.1016/j.expthermflusci.2013.10.004

65. Mehdipour R, Baniamerian Z, Delauré Y (2016) Three dimensional simulation of nucleate boiling heat and mass transfer in cooling passages of internal combustion engines. Heat Mass Transf 52(5):957-968. https://doi.org/10.1007/s00231-015-1611-6

66. Torregrosa AJ, Broatch A, Olmeda P, Martín J (2010) A contribution to film coefficient estimation in piston cooling galleries. Exp Therm Fluid Sci 34(2):142-151. https://doi.org/10.1016/j.expth ermflusci.2009.10.003

67. Liu YC, Guessous L, Sangeorzan BP, Alkidas AC (2014) Laboratory experiments on oil-jet cooling of internal combustion engine pistons: area-average correlation of oil-jet impingement heat transfer. J Energy Eng 141(2):C4014003. https://doi.org/10.1061/ (ASCE)EY.1943-7897.0000227

68. Peng W, Jizu L, Minli B, Yuyan W, Chengzhi Hu, Liang Zhang (2014) Numerical simulation on the flow and heat transfer process of nanofluids inside a piston cooling gallery. Numer Heat Transf Part A Appl 65(4):378-400. https://doi.org/10.1080/10407 782.2013.832071

69. Payri F, Olmeda P, Martín J, Carreño R (2014) A new tool to perform global energy balances in di diesel engines. SAE Int J Engines 7(1):43-59. https://doi.org/10.4271/2014-01-0665

70. Kikusato A, Kusaka J, Daisho Y (2015) A numerical study on predicting combustion chamber wall surface temperature distributions in a diesel engine and their effects on combustion, emission and heat loss characteristics by using a $3 \mathrm{~d}$-cfd code combined with a detailed heat transfer model. Technical report, SAE Technical Paper. https://doi.org/10.4271/2015-01-1847

71. Martín J, Novella R, García A, Carreño R, Heuser Benedikt, Kremer Florian, Pischinger Stefan (2016) Thermal analysis of a light-duty ci engine operating with diesel-gasoline dual-fuel combustion mode. Energy 115:1305-1319. https://doi.org/10.1016/j.energy.2016.09.021

72. Broatch A, Olmeda P, Margot X, Escalona J (2019) New approach to study the heat transfer in internal combustion engines by $3 \mathrm{~d}$ modelling. In J Therm Sci 138:405-415. https://doi.org/10.1016/j. ijthermalsci.2019.01.006 